\title{
The impact of rainfall time series with different length in a landslide warning system, in the framework of changing precipitation trends
}

\author{
Samuele Segoni, Ascanio Rosi, Daniela Lagomarsino, Riccardo Fanti and Nicola Casagli
}

\begin{abstract}
Background: This study explores some possible impacts that climate change could have in regional scale landslide early warning systems based on rainfall thresholds. The early warning system of the Emilia Romagna region (Italy), was used as a case of study to assess how much the changing precipitation trends can affect the rainfall parameters used by the warning system and to assess whether the predictive power is higher when its thresholds are defined using long (60 years) rainfall time series or using a shorter (10 years) but more recent dataset.

Results: In our case of study, the use of recent but limited rainfall time series, although more representative of the contemporary rainfall regime, is a worse predictor compared to the longest possible rainfall datasets. The analysis of 60 -years-long rainfall series facilitated the identification of extreme and anomalous events, as they better stand out from the average time series.

Conclusions: This study proves that early warning systems should not be considered as a static product: the rainfall thresholds should be regularly updated, the measuring network should be maintained, and the dismissal of oldest sensors should be carefully evaluated as their long time series improve the forecasting effectiveness or warning systems.
\end{abstract}

Keywords: Rainfall, Landslide, Early warning, Climate change

\section{Background}

Landsliding is a natural hazard that is responsible for casualties and economical losses worldwide (Petley 2012). In temperate and Mediterranean climates, rainfall is the most common triggering factor, therefore landslide early warning systems at regional scale are generally based on the exceedance of statistical rainfall thresholds (Guzzetti et al. 2007; Guzzetti et al. 2008; Tiranti and Rabuffetti 2010; Cannon et al. 2011; Segoni et al. 2015a; Cucchi et al. 2015). Such thresholds are commonly developed from two kinds of input data: a rainfall dataset and a landslide inventory. Neglecting any aspect related to the triggering mechanism, which is very site specific and that could be hardly generalized at the regional

\footnotetext{
* Correspondence: samuele.segoni@unifi.it

Department of Earth Sciences, University of Firenze, Via La Pira 4, 50121 Florence, Italy
}

scale, statistical techniques are used to find an empirical relationship between landslide initiation and rainfall parameters and to define a mathematical formula (threshold) that separates rainfall conditions associated to landsliding and rainfall conditions that are not. In the literature, a wide variety of rainfall parameters have been effectively used to define rainfall thresholds, including intensity and duration (Cannon et al. 2011; Segoni et al. 2014a, b; Caine 1980; Guzzetti et al. 2008; Rosi et al. 2012; Nikolopoulos et al. 2015), cumulative event rainfal and duration (Innes 1983; Vennari et al. 2014), cumulative event rainfall and soil saturation (Ponziani et al. 2012), antecedent rainfall (Govi and Sorzana 1980; Glade et al. 2000), antecedent rainfall as measured over a given duration (Pasuto and Silvano 1998; Wilson 2000; Chleborad 2003) and other parameters (Guzzetti et al. 2007 and references therein). 
This variety of parameters depends mainly on the quantity and quality of data (e.g. peak intensity cannot be properly assessed when rainfall data are measured at daily intervals) and on the physical constrains of the study area, above all the landslide typology (Lagomarsino et al. 2015). Indeed, there is a general agreement in recognizing that debris flows and shallow landslides are preferentially triggered by short and intense rainfalls (Campbell 1974; Crosta 1998), therefore, when trying to predict shallow movements, intensity - duration thresholds are traditionally preferred (Caine 1980; Guzzetti et al. 2008). Conversely, deep-seated landslides are usually influenced by prolonged and less intense rainfall events (Bonnard and Noverraz 2001; Martelloni et al. 2012); therefore, the antecedent rain plays a crucial role and rainfall thresholds are often based on rainfall parameters that refer to time intervals that may range from a few days (Crosta 1998; Heyerdahl et al. 2003) to several months (Lagomarsino et al. 2013; De Vita 2000).

Rainfall thresholds have been defined at every scale of analysis; in particular, they can be conveniently used in regional scale landslide warning systems (Martelloni et al. 2012; Giannecchini et al. 2012; Lagomarsino et al. 2013; Segoni et al. 2015a; Tiranti and Rabuffetti 2010). All warning systems based on rainfall thresholds have the same basic principle: the formula representing the threshold is valid for the past and is considered valid also for the future; thus, if the system predicts rainfall conditions similar to those that in the past were associated to landslide initiations, a warning is issued.

This assumption is weakened by climate change and consequent changing of precipitation trends, which have been observed by many scientists (IPCC 2013; Parmesan and Yohe 2003). Concerning landslide rainfall thresholds, some authors pointed out that their validity is limited in time as constant updates are necessary to account for the changing precipitation characteristics (Floris et al. 2010; Arnone et al. 2013; Rosi et al. 2015). Some authors point out that these changing trends have tangible consequences in the definition of statistical rainfall thresholds (Wilson 2000; Floris et al. 2010; Quadrelli et al. 2001; Martina et al. 2010), hence the need of performing periodic updates of the thresholds to have a fully functional operating EWS (Lagomarsino et al. 2013; Rosi et al. 2015).

Moreover, the recent changes in precipitation regimes bring to another issue in rainfall thresholds analysis: on one hand, statistical analyses are more robust if a long dataset is used and, according to the basic principles of statistics, the longest available time series should be used. On the other hand, if current rainfall regimes are different from those of a few decades ago, then only a more limited and recent dataset could be considered representative of the present precipitation regime and rainfall-landsliding relationship. To our knowledge, this ambiguity has not been fully addressed in the existing literature and the present study proposes a case of study to contribute to fill this gap.

This study aims to explore some possible impacts that climate changes can have in a regional scale landslide early warning system based on rainfall thresholds. The Emilia Romagna region (Italy), along with its early warning system named SIGMA (Sistema Integrato Gestione Monitoraggio Allerta) (Martelloni et al. 2012; Lagomarsino et al. 2013), was used as a case of study to: i) assess how much the changing precipitation trends are affecting the rainfall parameters used by the early warning system; ii) assess whether the early warning system provides better results when its thresholds are defined using long (60 years) rainfall time series or using a shorter (10 years) but more recent dataset.

\section{Methods}

\section{Test site: Emilia Romagna region}

Emilia Romagna is a region in northern Italy that can be divided in two parts: the northern and eastern part is occupied by the alluvial plain of the Po River, while the southern and western part is occupied by the Apennines (Fig. 1).

The regional landslide warning system focuses only on landslide prone areas; therefore, the flat area of the Po plain is not encompassed in this study.

The Apennines are a thrust and fold belt with a very complex tectonic and geological setting. In the study area, the bedrock consists mainly of flysch, which is composed of alternating massive rocks (mainly sandstones and calcarenites) and pelitic layers of variable thickness (Vai and Martini 2001). Argillaceous geological formations are abundant as well and, during the Holocene, they were pervasively affected by large landslides with recurrent periods of reactivation.

Emilia Romagna is very susceptible to landsliding: here the national inventory of landslides (IFFI) reports 70,037 among active, dormant and inactive landslides (Trigila et al. 2010). The most frequent phenomena are deepseated rotational-translational slides (affecting mainly flysch), slow earth flows (occurring in clayey lithologies) and complex movements (typically rotational failures at the head progressively changing into translational movements throughout the body and toe) (Martelloni et al. 2012; Bianchi and Catani 2002; Benedetti et al. 2005). Rapid shallow landslides are recurrent as well and some authors report an increased frequency in the last few years (Lagomarsino et al. 2013; Martina et al. 2010).

IFFI inventory is considered one of the most complete landslides inventory of Italy, and it can be used to provide an overview on landslide phenomena in Emilia Romagna (Segoni et al. 2015b), as it provides accurate 


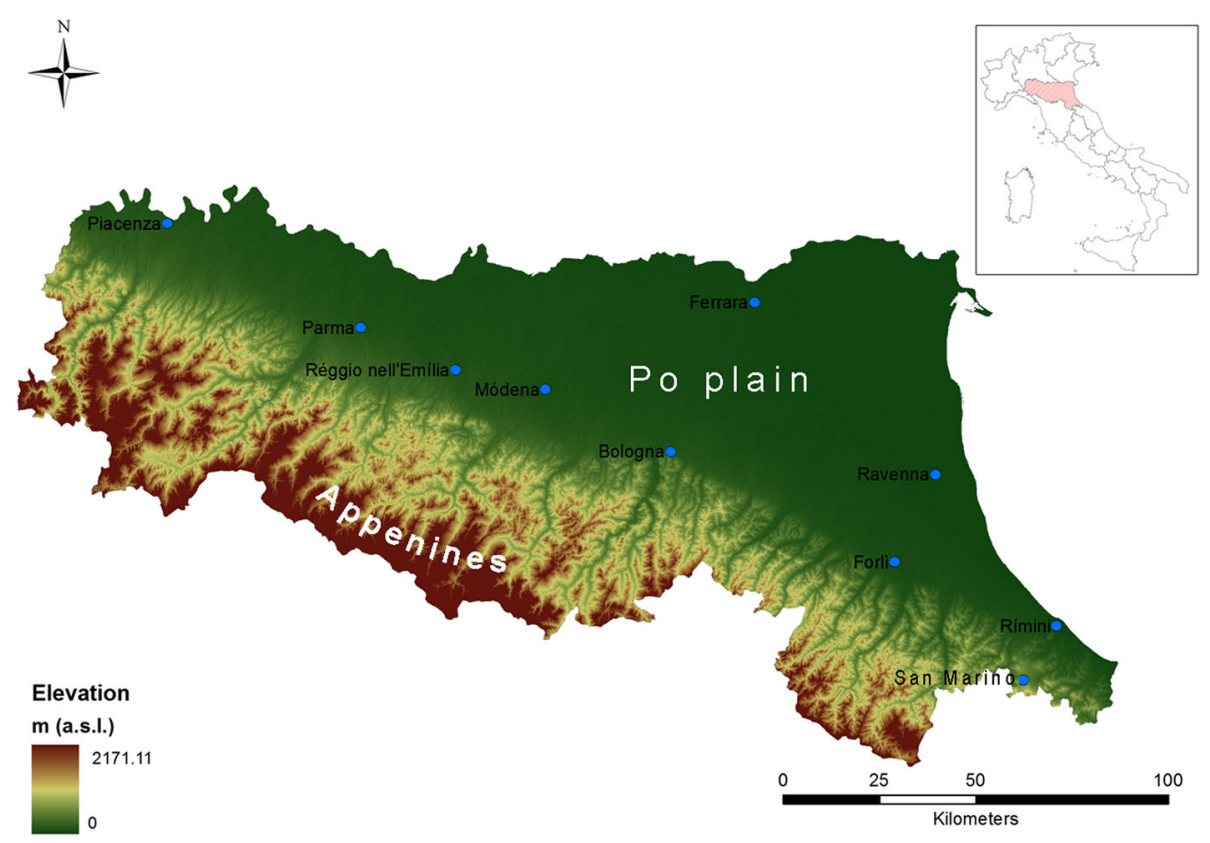

Fig. 1 Location of the study area; the test site is limited to the landslide susceptible areas, which correspond to the hilly and mountainous territories

mapping of all landslide bodies and useful additional information (e.g. state of activity or landslide typology). However, it could not be used to develop the warning system and to carry out the elaborations accounted for in this manuscript, because it does not provide the exact timing of triggering of each landslide, which is a mandatory information to develop, calibrate and validate rainfall thresholds and warning systems (Guzzetti et al. 2007; Rosi et al. 2015). Therefore, the landslide database used in this work is a regional inventory made up of official records of the regional civil protection agency, spanning through the years 2004 to 2010, and containing 1680 landslides. In most of the cases, the timing of the landslides is known with daily detail, thus matching perfectly the daily outputs of SIGMA warning system. However, this database was compiled for administrative purposes: it contains information about the damaged properties but does not always provide further details about landslides; thus, most of the times, the landslide typology is unknown.

Landslides affecting Emilia Romagna are triggered by rainfall and two different kinds of precipitation events can be associated with the initiation of different landslide typologies: deep-seated landslides and earthflows are usually activated by moderate-intensity but exceptionally prolonged periods of rainfalls (Martelloni et al. 2012; Benedetti et al. 2005), while shallow landslides are commonly caused by short but exceptionally intense rainstorms.
The study area is characterized by a typical Mediterranean climate with warm and dry summers (approximately from May to October) and mild/cool and wet winters (approximately from November to April).

\section{SIGMA early warning system}

To account for the hazard connected to rainfall triggered landslides in Emilia Romagna, the regional Civil Protection Agency uses a warning system called SIGMA (Sistema Integrato Gestione Monitoraggio Allerta), which is based on empirical rainfall thresholds. The system is explained in detail in Martelloni et al., (2012) and Lagomarsino et al. (2013), and that can be briefly outlined as follows.

The Emilia Romagna region is subdivided into 8 Alert Zones (AZ) and each of them is monitored by a variable number of rain gauges (for a total of 25 in the whole region). Each rain gauge is considered representative of a Territorial Unit (TU), defined on the basis of relatively homogeneous geological, geomorphological and topographical characteristics (Fig. 2) (Martelloni et al. 2012; Lagomarsino et al. 2013).

All rain gauges satisfy the following characteristics: i) presence of a long historical series of rainfall recordings (60 years in most of the cases); ii) connection to a regional network that allows remote real-time measurements at hourly time steps; iii) representativeness of the TU meteorology, as demonstrated by a quantitative comparison with all other rain gauges of the same $\mathrm{TU}$ (Lagomarsino et al. 2013). 


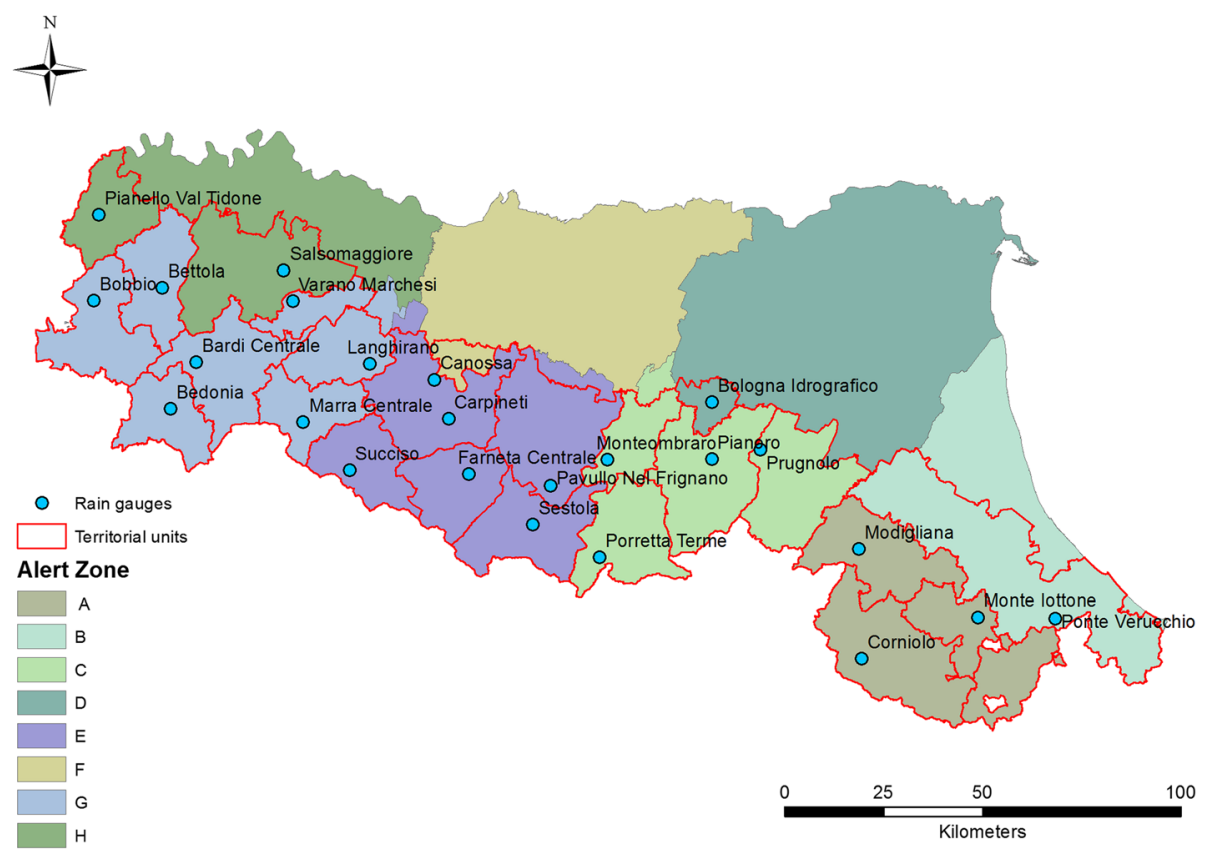

Fig. 2 Alert Zones, Territorial Units and rain gauges used in the SIGMA warning system of the Emilia Romagna region

A statistical analysis was carried out on the historical rainfall series of each rain-gauge (Martelloni et al. 2012). The result of this analysis was to define the rainfall records in terms of standard deviation $(\sigma)$ from the mean value. This allowed drawing the $\sigma$ curves, which define the amount of rain per day(s) as a multiple of the standard deviation above the mean historical value. For the most part of the rain gauges, the recordings begin in 1953 .

For each territorial unit a catalogue of historical landslides is compared with the rainfall records in order to define the $\sigma$ curves to be used as rainfall thresholds for the occurrence of landslides (Martelloni et al. 2012).

In the warning system, the measured and the forecasted rainfall are compared with these thresholds. Since the response of slope stability to rainfall may be complex, SIGMA is based on a decision algorithm aimed at identifying short but exceptionally intense rainfalls and mild but exceptionally prolonged rains (Fig. 3): while the first ones are commonly associated to shallow landslides, the latter ones are mainly associated with deep-seated landslides. In the first case, the rainfall threshold is defined by high $\sigma$ values (up to 3.5) and short durations (1, 2 or 3 days); in the second case, $\sigma$ values are lower (to a minimum of 1.5) but the decision algorithm checks durations that may get to 265 days.

Each Territorial Unit has its own $\sigma$ curves (defined by a statistical analysis on the rainfall series of its reference rain gauge) and its decision algorithm may use different multiples of $\sigma$ (defined by a calibration against welldocumented landsides).
Finally, the warning system combines the outputs provided by the decision algorithm and aggregates them at the Alert Zone level (Lagomarsino et al. 2013).

As requested by the current regional laws, the warning system is run at least daily to provide a distinct criticality level for each Alert Zone. Normally, at the ordinary criticality level the only countermeasure is keeping a more frequent monitoring activity, while moderate and high criticalities can give way to real alerts addressed to municipalities and to other environmental agencies.

It should be stressed that the objective of regional warning systems based on empirical rainfall thresholds is not to forecast where and when a single landslide may occur, but is to warn when a more or less wide portion of territory may be critically exposed to one or more landslides (Guzzetti et al. 2007; Vennari et al. 2014; Rosi et al. 2016). However, SIGMA encompasses some features addressed to reduce the spatial uncertainty. First of all, the system is not based on a single threshold for the whole region: each $\mathrm{AZ}$ is monitored independently and may have alert levels different from those of the other AZs. Moreover, a combination with a landslide susceptibility map improves the spatial accuracy of the model (Segoni et al. 2015b).

The warning system has also an additional module that accounts for the effects of snowmelt and snow accumulation (Martelloni et al. 2013).

\section{Analysis of time series}

The SIGMA warning system has been operated in Emilia Romagna for several years and its performance 


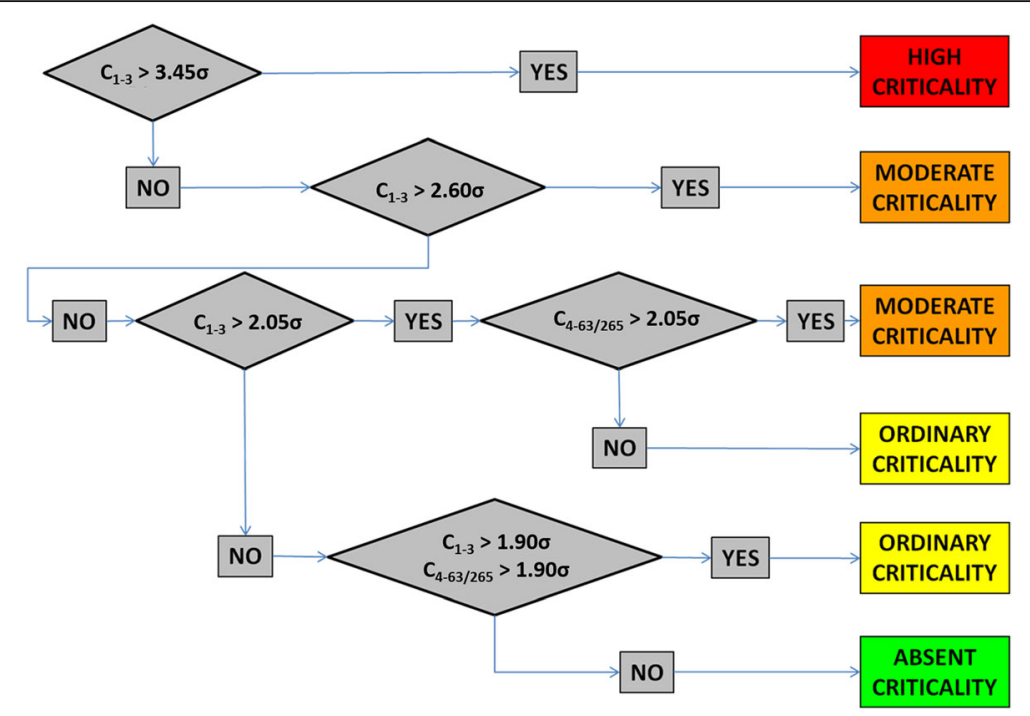

Fig. 3 The decisional algorithm at the core of the SIGMA warning system. $C_{1-3}$ is the cumulative rainfall measured on the last day, the last two days and the last three days. $C_{4-63 / 265}$ is the cumulative rainfall measured in the last 4 days, 5 days, ... up to 63 days in the dry season or up to 265 days in the wet season. The figure gives as an example the $\sigma$ levels of TU number 4. Further details can be found in Martelloni et al. 2012

is episodically evaluated (Martelloni et al. 2012; Lagomarsino et al. 2013; Lagomarsino et al. 2015). In this work, a different version of SIGMA (S10 henceforth) is applied and compared to the original one ( $\mathrm{S} 60$ henceforth). The only different feature of S10 is that, to obtain the $\sigma$ curves, the statistical analyses are performed using only the rainfall records of the last 10 years, instead of using the complete historical time series of each rain gauge (typically about 60 years). The analyses are carried out on 22 out of 25 rain gauges: the remaining three have shorter time series (up to 30 years), and were excluded from the analyses, as their time series are not long enough for the purpose of this work.

To assess if climate change affects the rainfall regime of Emilia Romagna, which in turn may affect the regional landslide early warning system, the $\sigma$ curves of S60 and the $\sigma$ curves of S10 were compared, along with some basic statistical properties (mean annual precipitation, mean daily precipitation, percentage of rainy days) of the different rainfall datasets.

In a second part of the study, the rainfall records from 2004 to 2010 were used to simulate the performance of S10 if used in the regional early warning system. The landslide database of the same period was compared with the model daily outputs to count both correct predictions and errors (false alarms and missed alarms). The performances of S10 were compared to those obtained by $\mathrm{S} 60$ in the same reference period, which had previously been published (Lagomarsino et al. 2013).

\section{Results}

\section{Variation in rainfall values}

First, for every reference rain gauge used by SIGMA, we compared the mean annual and daily precipitation values (MAP and MDP) as measured over the last 60 years with those calculated for the last 10 years. As can be seen from Table 1, there is a high variability, as several rain gauges show negligible or small variations, some show a marked increase and some a marked decrease in some or in all variables taken into account. Overall, the average yearly and daily amounts of rainfall of the last 10 years show a small decrease $(-1 \%)$ with respect to the last 60 years. Figure 4 shows that eastern territorial units are characterized by a marked decrease in MAP values, while in the rest of the region the spatial distribution of MAP variations does not seem to follow a regular scheme and does not correlate with latitude/longitude, nor with elevation (plot in upper right corner of Fig. 4).

The same irregular pattern is observed when the rainy days (percentage, in a year, of days with total precipitation over $1 \mathrm{~mm}$ ) are taken into account.

A more complete insight on the Emilia Romagna rainfall changing trends can be obtained comparing the $\sigma$ curves. Basically, $\sigma$ curves express how much precipitations of a given duration and amount can be considered "exceptional", where the exceptionality is statistically assessed in terms of multiples of the standard deviation.

Figure 5 compares the $\sigma$ curves obtained using 10 years and 60 years datasets in some rain gauges, in order to highlight the main common trends and the main differences that could be encountered in the territorial units of Emilia Romagna. 
Table 1 Comparison between mean annual precipitation (MAP) and mean daily precipitation (MDP) as measured over the last 60 years and the last 10 years

\begin{tabular}{|c|c|c|c|c|c|c|c|c|}
\hline \multirow[t]{2}{*}{ Rain Gauge } & \multicolumn{3}{|l|}{ 2003-2013 } & \multicolumn{3}{|l|}{ 1953-2013 } & \multicolumn{2}{|c|}{ Variation (\%) } \\
\hline & MAP (mm) & $\mathrm{MDP}(\mathrm{mm})$ & Rainy days $s^{\mathrm{a}}(\%)$ & MAP (mm) & $\mathrm{MDP}(\mathrm{mm})$ & Rainy days ${ }^{\mathrm{a}}(\%)$ & MAP & Rainy days ${ }^{2}$ \\
\hline Bardi & 1007.4 & 2.8 & 21.2 & 1043.9 & 2.9 & 28.9 & -3.5 & -7.7 \\
\hline Bedonia & 1368.8 & 3.8 & 23.2 & 1379.7 & 3.8 & 30.7 & -0.8 & -7.5 \\
\hline Bettola & 901.6 & 2.5 & 19.7 & 876.0 & 2.4 & 19.3 & 2.9 & 0.4 \\
\hline Bobbio & 828.6 & 2.3 & 19.1 & 890.6 & 2.4 & 25.6 & -7.0 & -6.5 \\
\hline Bologna & 814.0 & 2.2 & 18.6 & 781.1 & 2.1 & 27.2 & 4.2 & -8.6 \\
\hline Canossa & 828.6 & 2.3 & 20.0 & 792.1 & 2.2 & 11.7 & 4.6 & 8.3 \\
\hline Corniolo & 1157.1 & 3.2 & 22.9 & 1270.2 & 3.5 & 22.3 & -8.9 & 0.6 \\
\hline Farneta & 978.2 & 2.7 & 22.7 & 970.9 & 2.7 & 28.0 & 0.8 & -5.3 \\
\hline Langhirano & 861.4 & 2.4 & 20.1 & 854.1 & 2.3 & 20.9 & 0.9 & -0.8 \\
\hline Marra & 1361.5 & 3.7 & 21.4 & 1372.4 & 3.8 & 37.1 & -0.8 & -15.8 \\
\hline Modigliana & 887.0 & 2.4 & 20.7 & 912.5 & 2.5 & 23.9 & -2.8 & -3.2 \\
\hline Montelottone & 788.4 & 2.2 & 26.0 & 890.6 & 2.4 & 30.0 & -11.5 & -4.0 \\
\hline Monteombraro & 919.8 & 2.5 & 21.1 & 963.6 & 2.6 & 25.2 & -4.5 & -4.1 \\
\hline Pavullo & 748.3 & 2.1 & 19.1 & 850.5 & 2.3 & 26.2 & -12.0 & -7.1 \\
\hline Pianello val Tidone & 839.5 & 2.3 & 19.7 & 741.0 & 2.0 & 13.7 & 13.3 & 6.0 \\
\hline Pianoro & 876.0 & 2.4 & 21.3 & 887.0 & 2.4 & 34.7 & -1.2 & -13.4 \\
\hline Porretta Terme & 1233.7 & 3.4 & 23.5 & 1200.9 & 3.3 & 40.7 & 2.7 & -17.3 \\
\hline Prugnolo & 788.4 & 2.2 & 19.2 & 781.1 & 2.1 & 14.2 & 0.9 & 5.0 \\
\hline Salsomaggiore & 934.4 & 2.6 & 19.4 & 901.6 & 2.5 & 23.6 & 3.6 & -4.2 \\
\hline Sestola & 1314.0 & 3.6 & 25.1 & 1335.9 & 3.7 & 31.9 & -1.6 & -6.8 \\
\hline Succiso & 1974.7 & 5.4 & 26.1 & 1941.8 & 5.3 & 31.5 & 1.7 & -5.4 \\
\hline Varano Marchesi & 952.7 & 2.6 & 20.1 & 1011.1 & 2.8 & 13.1 & -5.8 & 7.1 \\
\hline
\end{tabular}

${ }^{a}$ Number of days with rainfall exceeding $1 \mathrm{~mm} /$ day

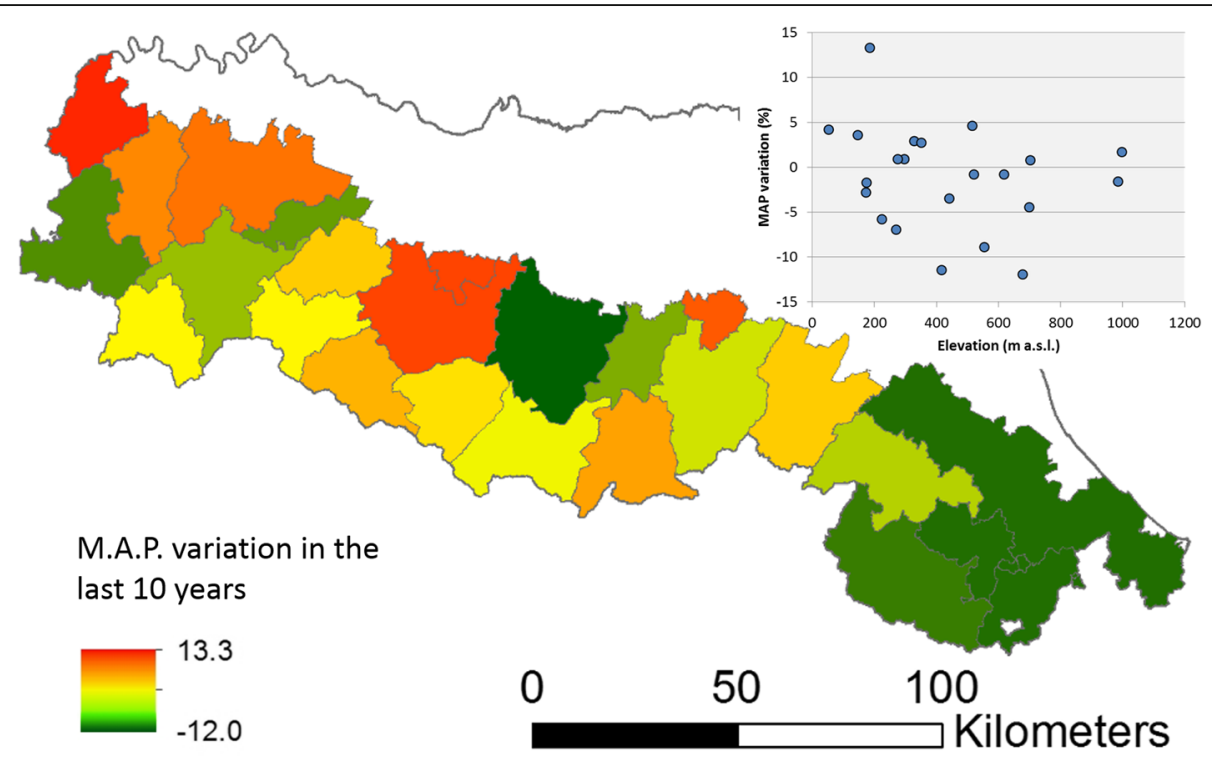

Fig. 4 Variation in the mean annual precipitation measured in the reference rain gauge of each territorial unit; in the upper right corner the mean annual precipitation variations are plotted versus the elevation of the reference rain gauge 


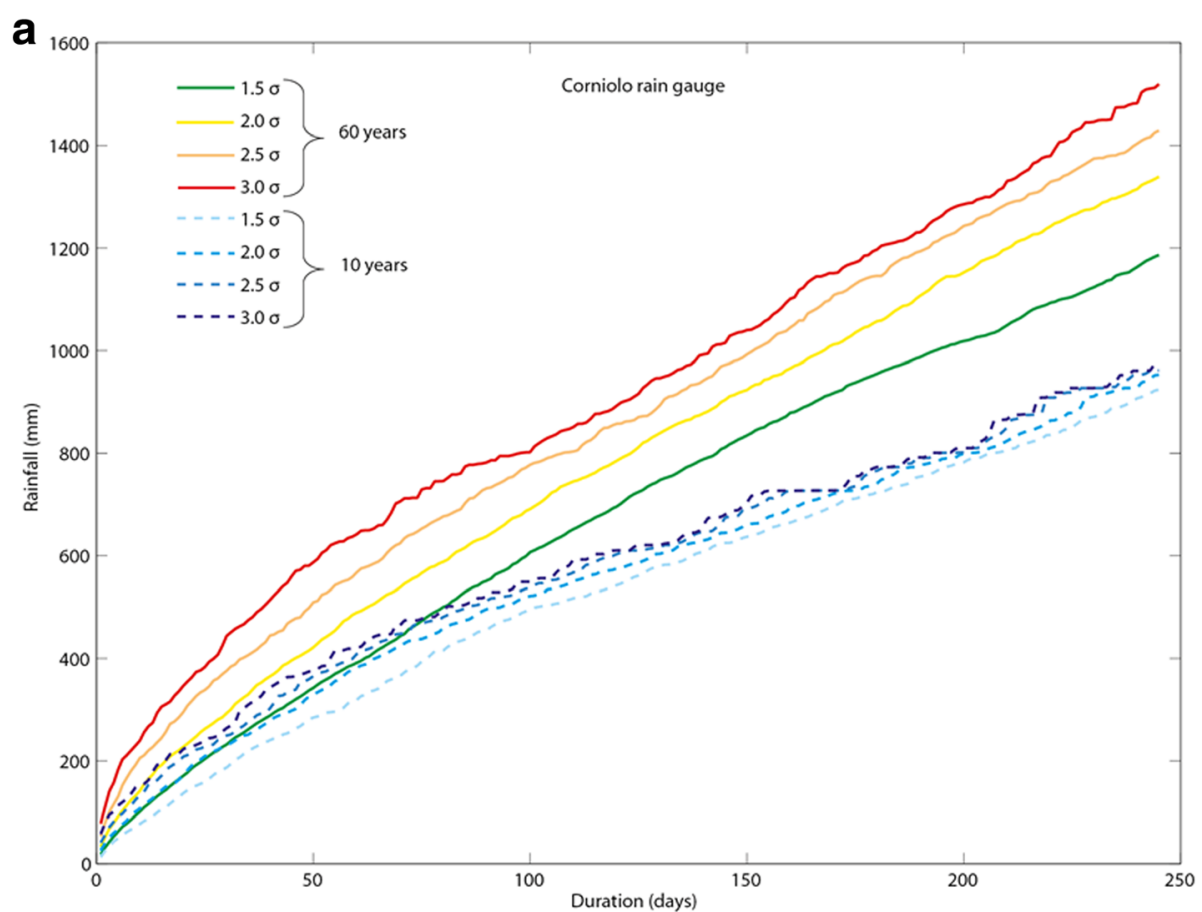

b

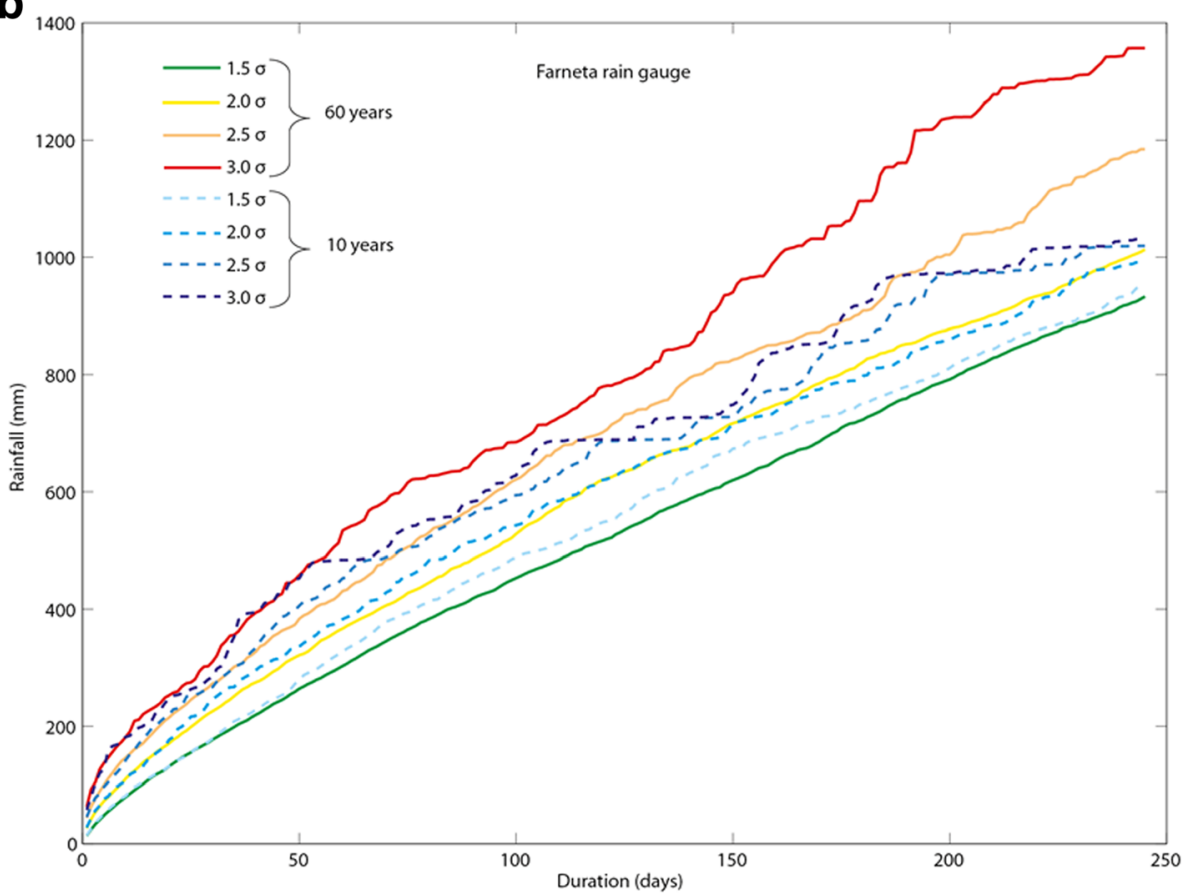

Fig. 5 Comparison of $\sigma$ curves calculated using 10 years and 60 years datasets. Most of the regional rain gauges have a trend similar to Corniolo rain gauge (a). However, a few cases exists where differences in $\sigma$ curves are less marked (b). The location of the rain gauges is displayed in Fig. 2

In general, the $\sigma$ curves pertaining to the last decade are markedly lower than the $\sigma$ curves pertaining to the last 60 years (Fig. 5). Only two pluviometers have slightly higher (Bologna) or substantially similar (Modigliana) $\sigma$ curves. This is verified especially for high multiples of $\sigma$, while for lower $\sigma$ multiples (i.e. $1.5 \sigma$ and $2.0 \sigma$ curves) 4 rain gauges (e.g. Farneta - Fig. 5) show similar or higher curves when the 10 years period is taken into account. Another interesting feature is that in almost all cases, for very short durations (i.e. a few days), the $3.0 \sigma$ curves calculated in 10 years are higher than those calculated in 60 years, even if at longer duration the trend is inverse. 
The only exceptions are Verano Marchesi, Pavullo, Monte Ombraro, Modigliana and Corniolo, which all have negative MAP variations (Table 1).

A common feature to all TUs is that the differences

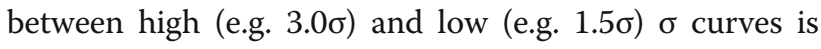
smaller if they are calculated using the last 10 years, rather than using the full 60 years dataset. This is particularly evident for long durations, when the curves seem to converge.

Generally, and especially for high multiples of $\sigma$, the $\sigma$ curves drawn using a 10 years dataset show an irregular pattern, with "flat" curve segments alternating with steep increments.

\section{Variation in SIGMA results}

The main objective of this work is to check if the performance of the warning system can be improved using $\sigma$ curves calculated on the last 10 years. To this end, an alternate version of SIGMA warning system (S10) was implemented using the 10 years $\sigma$ curves defined in the previous section. In each $\mathrm{TU}$, the decision algorithm was calibrated against past known landslides as in Martelloni et al. (2012). Afterwards, we simulated the performance of S10 using the rainfall measurements of the period 2004-2010 and we performed a validation: for each territorial unit, the simulated daily outputs of SIGMA were compared to the existing landslide database and classified as true positives (TP, correct prediction of landslide), true negatives ( $\mathrm{TN}$, no threshold exceedance and no landslide occurrence), false positives (FP, threshold exceedance and no landslide) and false negatives (FN, no threshold exceedance and landslide occurrence).

Concerning S60, the results of a validation procedure carried out with identical methodology are known (Lagomarsino et al. 2013). The validation statistics of both S10 and S60 were combined to define common performance indexes widely used in literature (Martelloni et al. 2012; Lagomarsino et al. 2015; Begueria 2005), in order to quantitatively compare the performances of S10 and S60 (Tables 2 and 3):

Sensitivity: $\mathrm{Se}=\mathrm{TP} /(\mathrm{TP}+\mathrm{FN})$; expressing the capability to properly classify rainfalls that triggered landslides; Specificity: $\mathrm{Sp}=\mathrm{TN} /(\mathrm{TN}+\mathrm{FP})$; expressing the capability to properly classify rainfalls that did not trigger landslides;

Table 2 Results of performance analysis and validation statistics of the S10 thresholds

\begin{tabular}{|c|c|c|c|c|c|c|c|c|c|c|}
\hline Rain Gauge & TP & $\mathrm{TN}$ & $F P$ & $\mathrm{FN}$ & $\mathrm{Se}$ & $S p$ & PPP & NPP & Eff & LR \\
\hline Bardi & 77 & 2384 & 88 & 6 & 0.93 & 0.96 & 0.47 & 1.00 & 0.96 & 26.06 \\
\hline Bedonia & 19 & 2459 & 75 & 2 & 0.90 & 0.97 & 0.20 & 1.00 & 0.97 & 30.57 \\
\hline Bettola & 25 & 2438 & 87 & 5 & 0.83 & 0.97 & 0.22 & 1.00 & 0.96 & 24.19 \\
\hline Bobbio & 44 & 2413 & 84 & 14 & 0.76 & 0.97 & 0.34 & 0.99 & 0.96 & 22.55 \\
\hline Bologna & 2 & 2427 & 126 & 0 & 1.00 & 0.95 & 0.02 & 1.00 & 0.95 & 20.26 \\
\hline Canossa & 8 & 2440 & 98 & 9 & 0.47 & 0.96 & 0.08 & 1.00 & 0.96 & 12.19 \\
\hline Corniolo & 54 & 2352 & 145 & 4 & 0.93 & 0.94 & 0.27 & 1.00 & 0.94 & 16.03 \\
\hline Farneta & 74 & 2362 & 91 & 28 & 0.73 & 0.96 & 0.45 & 0.99 & 0.95 & 19.56 \\
\hline Langhirano & 28 & 2417 & 96 & 24 & 0.54 & 0.96 & 0.23 & 0.99 & 0.95 & 14.10 \\
\hline M. Lottone & 72 & 2340 & 142 & 1 & 0.99 & 0.94 & 0.34 & 1.00 & 0.94 & 17.24 \\
\hline M. Ombraro & 30 & 2419 & 94 & 12 & 0.71 & 0.96 & 0.24 & 1.00 & 0.96 & 19.10 \\
\hline Marra & 13 & 2441 & 94 & 7 & 0.65 & 0.96 & 0.12 & 1.00 & 0.96 & 17.53 \\
\hline Modigliana & 60 & 2394 & 92 & 9 & 0.87 & 0.96 & 0.39 & 1.00 & 0.96 & 23.50 \\
\hline P. Verucchio & 42 & 2388 & 122 & 3 & 0.93 & 0.95 & 0.26 & 1.00 & 0.95 & 19.20 \\
\hline Pavullo & 59 & 2354 & 108 & 34 & 0.63 & 0.96 & 0.35 & 0.99 & 0.94 & 14.46 \\
\hline Pianello Val Tidone & 11 & 2409 & 132 & 3 & 0.79 & 0.95 & 0.08 & 1.00 & 0.95 & 15.13 \\
\hline Poretta Terme & 145 & 2295 & 89 & 26 & 0.85 & 0.96 & 0.62 & 0.99 & 0.95 & 22.71 \\
\hline Prugnolo & 14 & 2430 & 97 & 14 & 0.50 & 0.96 & 0.13 & 0.99 & 0.96 & 13.03 \\
\hline Salsomaggiore & 60 & 2410 & 75 & 10 & 0.86 & 0.97 & 0.44 & 1.00 & 0.97 & 28.40 \\
\hline Sestola & 125 & 2324 & 76 & 30 & 0.81 & 0.97 & 0.62 & 0.99 & 0.96 & 25.47 \\
\hline Succiso & 33 & 2442 & 70 & 10 & 0.77 & 0.97 & 0.32 & 1.00 & 0.97 & 27.54 \\
\hline Varano Marchesi & 66 & 2400 & 84 & 5 & 0.93 & 0.97 & 0.44 & 1.00 & 0.97 & 27.49 \\
\hline TOTAL & 1061 & 52738 & 2165 & 256 & 0.81 & 0.96 & 0.33 & 1.00 & 0.96 & 20.43 \\
\hline
\end{tabular}


Table 3 Results of performance analysis and validation statistics of the S60 thresholds

\begin{tabular}{|c|c|c|c|c|c|c|c|c|c|c|}
\hline Rain Gauge & TP & $\mathrm{TN}$ & $\mathrm{FP}$ & FN & $\mathrm{Se}$ & $S p$ & PPP & NPP & Eff & LR \\
\hline Bardi & 78 & 2398 & 74 & 5 & 0.94 & 0.97 & 0.51 & 1.00 & 0.97 & 31.39 \\
\hline Bedonia & 19 & 2462 & 72 & 2 & 0.90 & 0.97 & 0.21 & 1.00 & 0.97 & 31.84 \\
\hline Bettola & 25 & 2453 & 72 & 5 & 0.83 & 0.97 & 0.26 & 1.00 & 0.97 & 29.22 \\
\hline Bobbio & 46 & 2400 & 97 & 12 & 0.79 & 0.96 & 0.32 & 1.00 & 0.96 & 20.42 \\
\hline Bologna & 2 & 2402 & 151 & 0 & 1.00 & 0.94 & 0.01 & 1.00 & 0.94 & 16.91 \\
\hline Canossa & 8 & 2437 & 101 & 9 & 0.47 & 0.96 & 0.07 & 1.00 & 0.96 & 11.83 \\
\hline Corniolo & 55 & 2387 & 110 & 3 & 0.95 & 0.96 & 0.33 & 1.00 & 0.96 & 21.53 \\
\hline Farneta & 74 & 2343 & 110 & 28 & 0.73 & 0.96 & 0.40 & 0.99 & 0.95 & 16.18 \\
\hline Langhirano & 39 & 2403 & 100 & 13 & 0.75 & 0.96 & 0.28 & 0.99 & 0.96 & 18.77 \\
\hline M. Lottone & 72 & 2374 & 108 & 1 & 0.99 & 0.96 & 0.40 & 1.00 & 0.96 & 22.67 \\
\hline M. Ombraro & 30 & 2415 & 98 & 12 & 0.71 & 0.96 & 0.23 & 1.00 & 0.96 & 18.32 \\
\hline Marra & 13 & 2465 & 70 & 7 & 0.65 & 0.97 & 0.16 & 1.00 & 0.97 & 23.54 \\
\hline Modigliana & 61 & 2382 & 104 & 8 & 0.88 & 0.96 & 0.37 & 1.00 & 0.96 & 21.13 \\
\hline P. Verucchio & 43 & 2394 & 116 & 2 & 0.96 & 0.95 & 0.27 & 1.00 & 0.95 & 20.68 \\
\hline Pavullo & 60 & 2373 & 89 & 33 & 0.65 & 0.96 & 0.40 & 0.99 & 0.95 & 17.85 \\
\hline Pianello Val Tidone & 12 & 2385 & 156 & 2 & 0.86 & 0.94 & 0.07 & 1.00 & 0.94 & 13.96 \\
\hline Poretta Terme & 145 & 2285 & 99 & 26 & 0.85 & 0.96 & 0.59 & 0.99 & 0.95 & 20.42 \\
\hline Prugnolo & 14 & 2432 & 95 & 14 & 0.50 & 0.96 & 0.13 & 0.99 & 0.96 & 13.30 \\
\hline Salsomaggiore & 62 & 2356 & 129 & 8 & 0.89 & 0.95 & 0.32 & 1.00 & 0.95 & 17.06 \\
\hline Sestola & 125 & 2322 & 78 & 30 & 0.81 & 0.97 & 0.62 & 0.99 & 0.96 & 24.81 \\
\hline Succiso & 33 & 2455 & 57 & 10 & 0.77 & 0.98 & 0.37 & 1.00 & 0.97 & 33.82 \\
\hline Varano Marchesi & 66 & 2396 & 88 & 5 & 0.93 & 0.96 & 0.43 & 1.00 & 0.96 & 26.24 \\
\hline TOTAL & 1082 & 52719 & 2174 & 235 & 0.82 & 0.96 & 0.33 & 1.00 & 0.96 & 20.74 \\
\hline
\end{tabular}

Positive prediction power: $\mathrm{PPP}=\mathrm{TP} /(\mathrm{FP}+\mathrm{TP})$; the probability of correctly classifying a rainfall that triggered landslides;

Negative predication power: $\mathrm{NPP}=\mathrm{TN} /(\mathrm{TN}+\mathrm{FN})$; the probability of correctly classifying a rainfall that not triggered landslides.

Efficiency: Eff $=(\mathrm{TP}+\mathrm{TN}) /(\mathrm{TP}+\mathrm{TN}+\mathrm{FP}+\mathrm{FN})$; the percentage of correct predictions.

Likelihood ratio: $\mathrm{LR}=\mathrm{Se} /(1-\mathrm{Sp})$; a measure of the overall performances.

\section{Discussion}

\section{Changing rainfall trends}

In several zones of the Mediterranean area, the recent climatic trends are leading to shorter and more intense rainfalls (Floris et al. 2010). The trends observed in Emilia Romagna for the last 10 years seem coherent with this assumption. As noted by other studies (Tomozeiu et al. 2000), the influence of local factors such as topography and the proximity of Adriatic Sea to the East prevent a homogeneous response in the various TUs and, apparently, regular spatial patterns cannot be identified. However, we verified a general reduction of rainy days per year with respect to the average annual precipitations indicating a drying trend.

The presence of a trend leading to short and intense precipitations is corroborated by the analysis of the $\sigma$ curves, which provide relevant information about the rainfall trends of the various territorial units. In addition, the comparison between $\sigma_{10}$ and $\sigma_{60}$ curves revealed comparable behavior in the various territorial units.

In almost all TUs, at long durations and for mid-low $\sigma$ values, $\sigma$ curves are lower for S10 than for S60. As instance, for Bardi rain gauge (Fig. 6), $200 \mathrm{~mm}$ of rain in 15 days correspond to $2.5 \sigma$ from the average 60 years value and to $3 \sigma$ from the average 10 years value. This outcome suggests that, at present days, events characterized by very large rainfall amount fallen over very long durations are less common than some decades ago.

At short durations, we observed the opposite trend. As can be seen from Fig. 6, $140 \mathrm{~mm}$ of rain in 3 days could be considered exceptional if compared to the rainfall of the last 60 years (value above the $3 \sigma$ curve of $\mathrm{S60)}$. However, if the reference period is reduced to the last 10 years, the same amount is less anomalous and less critical (value below the $3 \sigma$ curve of S10). This means that short and intense rainfalls have become 


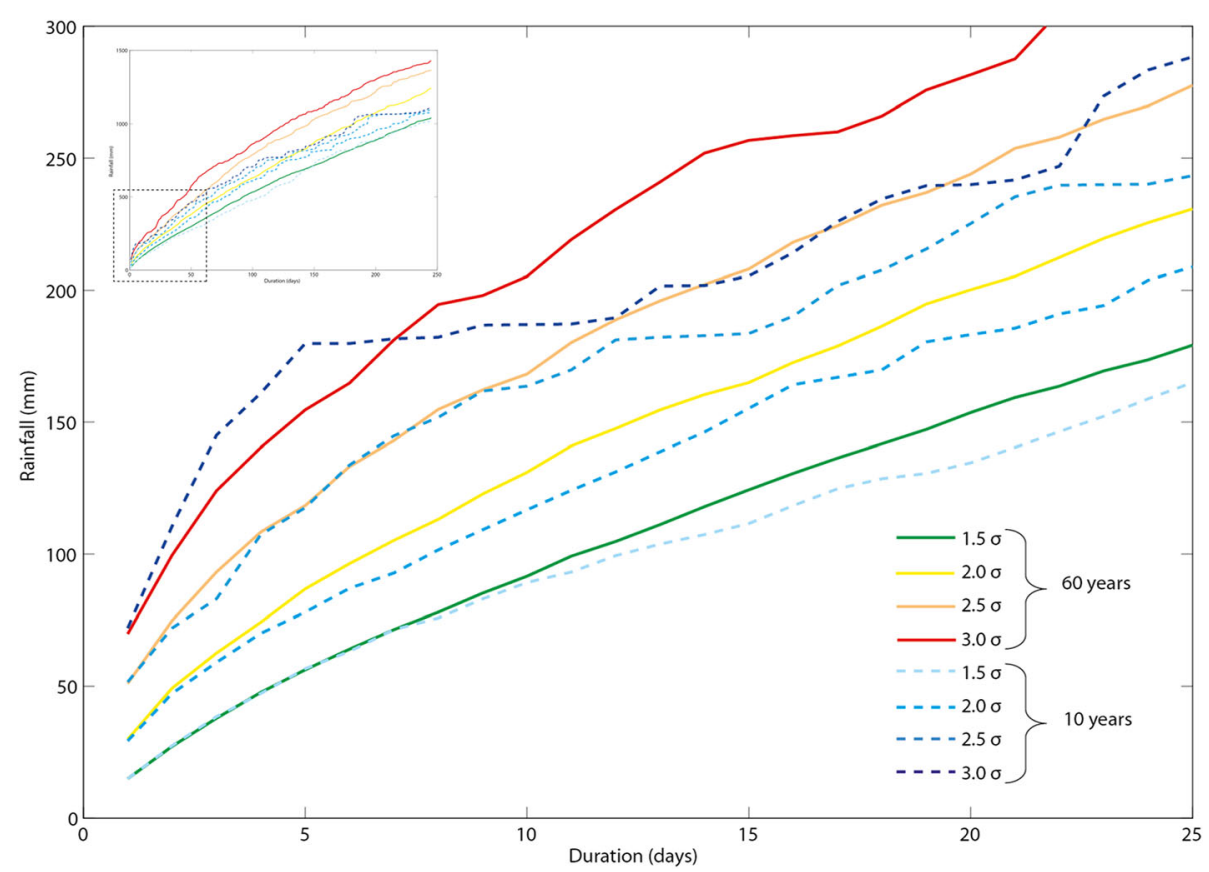

Fig. 6 Zoom of the $\sigma$ curves at short durations, Bardi rain gauge

more common than in the past decades and a higher rainfall amount is needed to consider a storm as exceptional, because more rainfall is needed to diverge significantly from the average values.

In addition, also the shape of S10 curves pertaining to the highest multiples of $\sigma$ shows evidences of a trend with increasing short-intense precipitation. In fact, as can be seen in Figs. 5 and 6, the curves have flat portions where at increasing time the rainfall amount and the $\sigma$ level remain stationary. These flat portions are usually followed by steep segments of the curve. This characteristic progressively diminishes at decreasing $\sigma$ multiples and is completely absent from S60 curves. This feature could be partially due to the reduced sample of the S10 time series, but it is also in accordance with the observed changing trends. In fact, because of the frequency of short duration and high intensity rainstorms, the moderate duration and intensity rainfalls are being progressively replaced by a complex concatenation of shorter but very intense episodes alterning with periods of no rain.

\section{Consequences in early warning system performance}

The last and most important part of this work focuses on the actual implications of changing precipitation trends in the effectiveness of the landslide forecasting system of Emilia Romagna. In simple words: provided that the rainfall regime is changing, is it better to update the rainfall thresholds of the warning system and to calibrate them against only the most recent and anomalous years of rain, or is it better to use the longest possible rainfall datasets, even if they may contain data pertaining to a rainfall regime that is different from the present one? According to the results of our analyses, we verified that, overall, the use of recent but limited rainfall time series results in poorer predictions than for the entire data series (S60) (Tables 2 and 3): in the test periods, 21 hazardous events, which were correctly predicted by $\mathrm{S} 60$, were missed by S10. This drawback is not compensated by the slight decrease of the false positive rate. Indeed, we verified a slight decrease in the value of the likelihood ratio (from 20.74 to 20.43), which is commonly being used to assess with a single statistic the global performance of a model (Begueria 2005; Lagomarsino et al. 2015).

If we look at the performance of the single territorial units (Tables 2 and 3), we observe a heterogeneous behavior. In 12 out of 22 TUs, S10 results in poorer predictions than S60. In 4 TUs, the capability of detecting landslides does not increase, however the number of false alarms is reduced, therefore the performance of the warning system is slightly improved. In $3 \mathrm{TUs}$, the number of correctly forecasted landslides diminishes, but this drawback is partially balanced by a decrease of false alarms. In 3 TUs, changes in performances were negligible. The use of S10 instead of S60 does not bring marked improvements in any of the TUs.

We also tried to investigate whether the use of S10 instead of S60 could produce some improvements at least in the forecasting of high-criticality events, that 
SIGMA identifies checking only higher multiples of standard deviations over short periods of time (3 days maximum, see Fig. 3). Basically, this subsample includes only short and exceptionally intense rainfalls. Again, the use of S10 produces in general poorer predictions than S10. Only in 5 TUs we verified a certain improvement (a slight reduction of false alarms), in 7 TUs false alarms are reduced but as a drawback some missed predictions are introduced, while in 8 circumstances the result is pejorative both in terms of missed alarms and true positives.

We explain these outcomes with the characteristics of the model at the core of the SIGMA warning system: the decisional algorithm is based on the concept that landslides occur in the case of rainfall events that can be considered exceptional either for the rainfall amount or for the duration (Figure 3). The analysis of 60-years-long rainfall series ease the identification of extreme and anomalous events because they better stand out from the average time series.

This is a crucial point, as for similar warning systems it is fundamental to identify rainfalls that may trigger landslides. Since the variation of meteorological forcing implies a variation in the activity of the geomorphological processes that shape the landscape, the application of similar early warning systems is even more effective (and needed at the same time) in a changing climate context.

\section{Conclusion}

We compared the last 10 years with the last 60 years of measurements from the rain gauges used by the regional landslide warning system of Emilia Romagna region (Italy). Considering some basic rainfall statistics used by the warning system, we observed variations in the local rainfall trends, with oscillations that are not homogeneously distributed in the territory and with relevant differences among the territorial units.

However, some indicators seem in accordance with the trend observed in other Mediterranean areas, that are leading to shortest and more intense rainfalls. This was confirmed in particular by the analysis of the $\sigma$ curves, which express how much a precipitation of a given duration and amount can be considered "exceptional", where the exceptionality is statistically assessed in terms of multiples of the standard deviation. In particular, we observed that, nowadays, rainfalls of short duration (i.e. a few days) need to have higher amounts to consistently diverge from the average values observed in the past decades. This outcome suggests that the climate change is bringing to relevant changes (even if not spatially homogeneous through Emilia Romagna) in the rainfall time series: intense rainfalls are concentrated on shorter durations than in the past decades and short events with extreme intensity are increasing in frequency.
The observed changes in rainfall trends could infer a change in landslide activity, with relevant implications for natural hazards assessment and civil protection activity. It is therefore of paramount importance to draw some conclusions that have a relevant impact in applied meteorology and in the operational applications of rainfall threshold to early warning systems.

First, this study clearly points out that, when landslides early warning systems are based on the identification of anomalous rainfall values by means of statistical analyses of rainfall time series, their effectiveness does not increase if only recent datasets are considered. In our case of study, the use of a short dataset representative of the recent changes in rainfall trends does not improve the identification of landslide occurrence. On the contrary, the use of long datasets (60 years in this work), provides the best results as it eases the identification of extreme rainfall values, which can stand out more markedly from the general trend observed over past decades.

In a period in which local civil protection agencies are planning the reorganization of their instrumental networks, these results suggest that it is of chiefly importance to maintain a certain degree of continuity for rain gauges with long time series and the dismissing or the displacement of "old" instruments should be considered carefully.

Furthermore, since the study pointed out that the longer the rainfall series, the better the warning system results, we can infer the importance of a constant update of the thresholds as soon as new data are available: the increased calibration sample leads to more robust and representative statistical analyses and helps to better account for the ongoing changes in precipitation trends and for the subsequent changes in the activity of geomorphological processes.

\section{Acknowledgments \\ This research has been financed by the Civil Protection Agency of the Emilia Romagna region. ARPA Emilia-Romagna (Regional Agency for Environmental Protection in the Emilia-Romagna region), is fully acknowledged for having provided part of the data used in this work.}

\section{Authors' contributions}

SS conceived and designed the research and drafted the manuscript. AR carried out the analysis on the rainfall data and took care of the figures. DL carried out the analysis on SIGMA warning system and performed the validation. RF participated in designing the study and helped in drafting the manuscript. NC participated in designing the study and revised the manuscript. All authors read and approved the final manuscript.

\section{Competing interests}

The authors declare that they have no competing interests.

Received: 26 October 2016 Accepted: 12 November 2016 Published online: 22 November 2016

\section{References \\ Arnone, E., D. Pumo, F. Viola, L.V. Noto, and G. La Loggia. 2013. Rainfall statistics changes in Sicily. Hydrology and Earth System Sciences 17: 2449-2458. Begueria, S. 2005. Validation and evaluation of predictive models in hazard assessment and risk management. Natural Hazards 37: 315-329.}


Benedetti, A., N. Casagli, V. Bosi, S. Dapporto, S. Ciolli, M. Palmieri, and F. Zinoni. 2005. Modello statistico per la previsione operativa dei fenomeni franosi nella regione Emilia-Romagna. Bollettino della Societa Geologica Italiana 124: 333-344.

Bianchi, F., and F. Catani. 2002. Landscape dynamics risk management in Northern Apennines (Italy). In Development and application of computer techniques to environmental studies, vol. 1, ed. C.A. Brebbia and P. Zannetti, 319-328. Southampton: WIT.

Bonnard, C.H., and F. Noverraz. 2001. Influence of climate change on large landslides: assessment of long term movements and trends. In Proceedings of the international conference on landslides causes impact and countermeasures, 121-138. Essen: Gluckauf.

Caine, N. 1980. The rainfall intensity-duration control of shallow landslides and debris flows. Geografiska Annaler 62: 23-27.

Campbell, R.H. 1974. Debris flows originating from soil slips during rainstorms in Southern California. Quarterly Journal of Engineering Geology 7: 339-349.

Cannon, S., E. Boldt, J. Laber, J. Kean, and D. Staley. 2011. Rainfall intensityduration thresholds for postfire debris-flow emergency response planning. Natural Hazards 59: 209-236.

Chleborad, A.F. 2003. Preliminary evaluation of a precipitation threshold for anticipating the occurrence of landslides in the Seattle, Washington Area, US Geological Survey Open-File Report 03, 463.

Crosta, G.B. 1998. Regionalization of rainfall thresholds: an aid to landslide hazard evaluation. Environmental Geology 35: 131-145.

Cucchi, A., I.Q. Valsecchi, M. Alberti, P. Fassi, M. Molari, and G. Mannucci. 2015. The alerting system for hydrogeological hazard in Lombardy Region, northern Italy: rainfall thresholds triggering debris-flows and "equivalent rainfall" method. Natural Hazards and Earth System Science Discussion 3: 269-290.

De Vita, P. 2000. Fenomeni di instabilità delle coperture piroclastiche dei Monti Lattari, di Sarno e di Salerno (Campania) ed analisi degli eventi pluviometrici determinanti. Quaderni di Geologia Applicata 7: 213-235.

Floris, M., A. D'Alpaos, C. Squarzoni, R. Genevois, and M. Marani. 2010. Recent changes in rainfall characteristics and their influence on thresholds for debris flow triggering in the Dolomitic area of Cortina d'Ampezzo, north-eastern Italian Alps. Natural Hazards and Earth System Sciences 10: 571-580.

Giannecchini, R., Y. Galanti, and G. D'Amato Avanzi. 2012. Critical rainfall thresholds for triggering shallow landslides in the Serchio River Valley (Tuscany, Italy). Natural Hazards and Earth System Sciences 12: 829-842. doi:10.5194/nhess-12-829-2012.

Glade, T., M.J. Crozier, and P. Smith. 2000. Applying probability determination to refine landslide-triggering rainfall thresholds using an empirical "antecedent daily rainfall model". Pure and Applied Geophysics 157: 1059-1079.

Govi, M., and P.F. Sorzana. 1980. Landslide susceptibility as function of critical rainfall amount in Piedmont basin (Northwestern Italy). Studia Geomorphologica Carpatho-Balcanica 14: 43-60.

Guzzetti, F., S. Peruccaci, M. Rossi, and C.P. Stark. 2007. Rainfall thresholds for the initiation of landslides in central and southern Europe. Meteorology and Atmospheric Physics 98: 239-267.

Guzzetti, F., S. Peruccacci, M. Rossi, and C.P. Stark. 2008. The rainfall intensityduration control of shallow landslides and debris flows: an update. Landslides 5: $3-17$.

Heyerdahl, H., C.B. Harbitz, U. Domaas, F. Sandersen, K. Tronstad, F. Nowacki, A. Engen, O. Kjekstad, G. Devoli, S.G. Buezo, M.R. Diaz, and W. Hernandez. 2003. Rainfall induced lahars in volcanic debris in Nicaragua and El Salvador: practical mitigation. In Proceedings of international conference on fast slope movements - prediction and prevention for risk mitigation, IC-FSM2003, 275-282. Naples: Patron Publication.

Innes, J.L. 1983. Debris flows. Progress in Physical Geography 7: 469-501.

IPCC - International Panel on Climate Change, 2013. Climate Change 2013: The Physical Science Basis. Contribution of Working Group I to the Fifth Assessment Report of the Intergovernmental Panel on Climate Change. 1535 pp. Cambridge and New York: Cambridge University Press.

Lagomarsino, D., S. Segoni, R. Fanti, and F. Catani. 2013. Updating and tuning a regional-scale landslide early warning system. Landslides 10: 91-97.

Lagomarsino, D., S. Segoni, A. Rosi, G. Rossi, A. Battistini, F. Catani, and N. Casagli. 2015. Quantitative comparison between two different methodologies to define rainfall thresholds for landslide forecasting. Natural Hazards and Earth System Sciences 15: 2413-2423. doi:10.5194/nhess-15-2413-2015.

Martelloni, G., S. Segoni, R. Fanti, and F. Catani. 2012. Rainfall thresholds for the forecasting of landslide occurrence at regional scale. Landslides 9: 485-495.
Martelloni, G., S. Segoni, D. Lagomarsino, R. Fanti, and F. Catani. 2013. Snow accumulation/melting model (SAMM) for integrated use in regional scale landslide early warning systems. Hydrology and Earth System Sciences 17: 1229-1240.

Martina, M.L.V., M. Berti, A. Simoni, E. Todini, and S. Pignone. 2010. Un approccio bayesiano per individuare le soglie di innesco delle frane. In Rainfall-induced landslides: mechanisms, monitoring techniques and nowcasting models for early warning systems, vol. 2, ed. L. Picarelli, P. Tommasi, G. Urcioli, and P. Versace. Naples: CIRAM.

Nikolopoulos, E.I., M. Borga, F. Marra, S. Crema, and L. Marchi. 2015. Debris flows in the eastern Italian Alps: seasonality and atmospheric circulation patterns. Natural Hazards and Earth System Sciences 15: 647-656.

Parmesan, C., and G. Yohe. 2003. A globally coherent fingerprint of climate change impacts across natural systems. Nature 421: 37-42.

Pasuto, A., and S. Silvano. 1998. Rainfall as a triggering factor of shallow mass movements. A case study in the Dolomites, Italy. Environmental Geology 35 184-189.

Petley, D. 2012. Global patterns of loss of life from landslides. Geology 40: 927-930.

Ponziani, F., C. Pandolfo, M. Stelluti, N. Berni, L. Brocca, and T. Moramarco. 2012. Assessment of rainfall thresholds and soil moisture modeling for operational hydrogeological risk prevention in the Umbria region (central Italy). Landslides 9: 229-237.

Quadrelli, R., V. Pavan, and F. Molteni. 2001. Winter Mediterranean precipitation variability and its links with upper-air large scale circulation anomalies. Climate Dynamics 5-6: 457-466.

Rosi, A., S. Segoni, F. Catani, and N. Casagli. 2012. Statistical and environmental analyses for the definition of a regional rainfall thresholds system for landslide triggering in Tuscany (Italy). Journal of Geographical Sciences 22 617-629.

Rosi A, Lagomarsino D, Rossi G, Segoni A, Battistini A, Casagli N, 2015. Updating EWS rainfall thresholds for the triggering of landslides. Natural Hazards. doi: 10.1007/s11069-015-1717-7

Rosi A, Peternel T, Jemec-Auflič M, Komac M, Segoni S, and Casagli N. 2016. Rainfall thresholds for rainfall-induced landslides in Slovenia. Landslides. doi: 10.1007/s10346-016-0733-3

Segoni, S., A. Rosi, G. Rossi, F. Catani, and N. Casagli. 2014a. Analysing the relationship between rainfalls and landslides to define a mosaic of triggering thresholds for regional scale warning systems. Natural Hazards and Earth System Sciences 14: 2637-2648.

Segoni S, Rossi G, Rosi A, and Catani F. 2014a. Landslides triggered by rainfall: a semiautomated procedure to define consistent intensity-duration thresholds. Computers and Geosciences. 63: 123-131

Segoni, S., A. Battistini, G. Rossi, A. Rosi, D. Lagomarsino, F. Catani, S. Moretti, and N. Casagli. 2015a. Technical note: an operational landslide early warning system at regional scale based on space-time-variable rainfall thresholds. Natural Hazards and Earth System Sciences 15: 853-861.

Segoni, S., D. Lagomarsino, R. Fanti, S. Moretti, and N. Casagli. 2015b. Integration of rainfall thresholds and susceptibility maps in the Emilia Romagna (Italy) regional-scale landslide warning system. Landslides 12: 773-785.

Tiranti, D., and D. Rabuffetti. 2010. Estimation of rainfall thresholds triggering shallow landslides for an operational warning system implementation. Landslides 7: 471-481.

Tomozeiu, R., A. Busuioc, V. Marletto, F. Zinoni, and C. Cacciamani. 2000. Detection of changes in the summer precipitation time series of the region Emilia-Romagna, Italy. Theoretical and Applied Climatology 67: 193-200.

Trigila, A., C. ladanza, and D. Spizzichino. 2010. Quality assessment of the Italian landslide inventory using GIS processing. Landslides 7: 455-470.

Vai, G.B., and I.P. Martini. 2001. Anatomy of an orogen: the Apennines and adjacent Mediterranean basins, 636. London: Kluwer Academic Publishers.

Vennari, C., S.L. Gariano, L. Antronico, M.T. Brunetti, G. lovine, S. Peruccacci, O. Terranova, and F. Guzzetti. 2014. Rainfall thresholds for shallow landslide occurrence in Calabria, southern Italy. Natural Hazards and Earth System Sciences 14: 317-330.

Wilson RC. 2000. Climatic variations in rainfall thresholds for debris-flow activity. In Proceedings of the EGS Plinius Conference on Mediterranean Storms, Maratea, Italy, 415-424. Cosenza: Bios. 